BNL-114361-2017-JA

\title{
Multimodal study of the speciations and activities of supported Pd catalysts during the hydrogenation of ethylene
}

\author{
S. Zhao, A. Frenkel
}

Submitted to Journal of Physical Chemistry C

August 2017

Chemistry Department

Brookhaven National Laboratory

\author{
U.S. Department of Energy \\ USDOE Office of Science (SC), \\ Basic Energy Sciences (BES) (SC-22)
}

\footnotetext{
Notice: This manuscript has been authored by employees of Brookhaven Science Associates, LLC under Contract No. DE- SC0012704 with the U.S. Department of Energy. The publisher by accepting the manuscript for publication acknowledges that the United States Government retains a non-exclusive, paidup, irrevocable, world-wide license to publish or reproduce the published form of this manuscript, or allow others to do so, for United States Government purposes.
} 


\section{DISCLAIMER}

This report was prepared as an account of work sponsored by an agency of the United States Government. Neither the United States Government nor any agency thereof, nor any of their employees, nor any of their contractors, subcontractors, or their employees, makes any warranty, express or implied, or assumes any legal liability or responsibility for the accuracy, completeness, or any third party's use or the results of such use of any information, apparatus, product, or process disclosed, or represents that its use would not infringe privately owned rights. Reference herein to any specific commercial product, process, or service by trade name, trademark, manufacturer, or otherwise, does not necessarily constitute or imply its endorsement, recommendation, or favoring by the United States Government or any agency thereof or its contractors or subcontractors. The views and opinions of authors expressed herein do not necessarily state or reflect those of the United States Government or any agency thereof. 


\section{Multimodal Study of the Speciations and}

\section{Activities of Supported Pd Catalysts During the Hydrogenation of Ethylene}

Shen Zhao, ${ }^{\dagger, \ddagger}, \perp$ Yuanyuan Li, ${ }^{\S, \perp}$ Deyu Liu, ${ }^{\dagger, \perp}$ Jing Liu, ${ }^{\S}$ Yao-Min Liu, ${ }^{\dagger}$ Dmitri N. Zakharov, ${ }^{\ddagger}$

Qiyuan Wu,,$^{\S}$ Alexander Orlov, ${ }^{\S}$ Andrew A. Gewirth, ${ }^{\dagger}$ Eric A. Stach, ${ }^{*},{ }^{\ddagger}$ Ralph G. Nuzzo, ${ }^{*},+$

Anatoly I. Frenkel ${ }^{*}$, , \#

† Department of Chemistry, University of Illinois, Urbana, IL 61801

‡ Center for Functional Nanomaterials, Brookhaven National Laboratory, Upton, NY 11973

$\S$ Department of Materials Science and Chemical Engineering, Stony Brook University, Stony

Brook, NY 11794

\# Division of Chemistry, Brookhaven National Laboratory, Upton, NY 11973 


\section{ABSTRACT}

In this work we describe a multi-modal exploration of the atomic structure and chemical state of silica-supported palladium nanocluster catalysts during the hydrogenation of ethylene in operando conditions that variously transform the metallic phases between hydride and carbide speciations. The work exploits a microreactor that allows combined multi-probe investigations by high resolution transmission electron microscopy (HR-TEM), X-ray absorption fine structure (XAFS), and microbeam IR ( $\mu$-IR) analyses on the catalyst under operando conditions. The work specifically explores the reaction processes that mediate the interconversion of hydride and carbide phases of the Pd clusters in consequence to changes made in the composition of the gasphase reactant feeds, their stability against coarsening, the reversibility of structural/compositional transformations, and the role that oligomeric/waxy byproducts (here forming under hydrogen-limited reactant compositions) might play in modifying activity. The results provide new insights into structural features of the chemistry/mechanisms of Pd catalysis during the selective hydrogenation of acetylene in ethylene-a process simplified here in the use of binary ethylene/hydrogen mixtures. These explorations, performed in operando conditions, provide new understandings of structure-activity relationships for Pd catalysis in regimes that actively transmute important attributes of electronic and atomic structures. 


\section{INTRODUCTION}

The hydrogenation of unsaturated hydrocarbons is one of the most widely used industrial catalytic processes. ${ }^{1-3}$ Whether in the production of fuels or large volume chemicals (e.g. low molecular weight olefins) from oil feedstocks, numerous catalytic reforming and (de)hydrogenation steps are required to effect these conversions. ${ }^{4-5}$ There has been considerable attention given in research to the discovery of new catalysts that can efficiently and costeffectively mediate the conversions of $\mathrm{C}-\mathrm{H}$ bonds as are required by such processes. Specific to hydrogenation reactions, a wide variety of catalyst materials have been studied under a broad range of experimental conditions. ${ }^{6-8}$ For the high temperature and pressure ambients associated with many large scale industrial processes, the use of supported noble metal nanoparticle (NPs) catalysts predominates due to their high activity, good long term stability, and ease of regeneration and recovery. ${ }^{9-11}$ Hydrogenation processes can also contribute other benefits (as well complications) to the conversions occurring in process streams beyond those suggested above-cases where the dominant mechanisms of action involve selective, and variously reversible, forms of C-H and/or C-C bond transformations. Highly active catalysts, for example, might also promote the reductive cleavage of C-C sigma bonds (hydrogenolysis), which is not desirable when it leads to an inefficient utilization of the hydrocarbon resource of the process feed. Catalytic hydrogenation chemistries also play a critical role in purification processes used in the industrial production fuels and chemicals, using them to selectively remove/convert impurities that would otherwise interfere with subsequent conversion steps. An important exemplar of the latter is catalytic hydrodesulfurization, which is used to remove S heteroatoms

from oil prior to its conversion to useful products. ${ }^{12}$ Another interesting example is one related to a selective chemistry for the addition of dihydrogen to unsaturated C-C bonds, specifically the 
selective catalytic hydrogenation of acetylene as an impurity in ethylene. ${ }^{13-14}$ The presence of acetylene, formed as an impurity during hydrocracking, poisons the downstream Ziegler-Natta catalysts used to polymerize ethylene and has to be removed using a selective hydrogenation process. High selectivity for its conversion to ethylene under hydrocarbon rich process conditions is important to prevent deleterious coproduction of ethane. Given the large global production of polyethylene, the complex interplay of activity and selectivity become critical metrics for evaluating catalyst performance.

As noted above, supported Pd catalysts, and a number of bimetallic compositions (notably, PdAg), afford good activities and selectivities for the selective hydrogenation of acetylene in ethylene rich environments and have been much studied for this reason. ${ }^{15-21}$ Important understandings of the mechanisms of action by these materials have been developed as a result, although important questions still remain as to the nature and compositional fluxionality of the structures that might result as a consequence of the precise conditions present in the environments of their use. Issues of particular interest are the sensitivities of the catalyst's structure and composition to the attributes of the gas-phase species contacting them, and the influences that variables such as temperature and absolute pressure might engender. Are the atomic and electronic structures of these catalysts fixed or can they in fact be transmuted in reaction conditions (notably in ways that vary more broadly from the well-characterized parent metallic and various hydride phases of Pd)? A second, and perhaps more overarching, question relates to how the structural/compositional fluxionality, as might be present, acts to impact selectivity, where the concern for most Pd-based catalysts remains activities that lead to both the over-hydrogenation of an alkyne/alkene feed (producing alkanes) and a correlated activity yielding a complex mixture of oligomeric hydrocarbons. ${ }^{22-26}$ The impacts of the latter species 
(which we show in this work present in part a rich speciation of even chain hydrocarbonsalkanes, alkenes, and polyenes—analogous to the "Green Oils" noted in industrial processes) on the catalyst's structure and function are not understood. ${ }^{13,}{ }^{27-29}$ Could these species, in terms of the bonding interactions and other physical associations they might have with the metal clusters' surfaces, lead to modifications of bonding that could impact activity?

There exists a body of literature that provides insight into the structural attributes of these catalysts as it might relate to their sensitivities in operando conditions. It is now well established that an active (indeed the most active) form of a supported Pd hydrogenation catalyst is a hydride phase that forms within hydrogen rich ambients. Recent reports further suggest that supported Pd NPs can also form a phase with subsurface carbon—a Pd carbide—in olefin rich ambients, ${ }^{30-31}$ a speciation that has a very different adsorption affinities for $\mathrm{C}_{2} \mathrm{H}_{2} / \mathrm{C}_{2} \mathrm{H}_{4}$ than does either Pd metal or its hydride. ${ }^{25,} 32-33$ Such an intercalation of carbon would likely modify selectivity in the hydrogenation process by weakening the adsorption of $\mathrm{C}_{2} \mathrm{H}_{4}{ }^{25-26,34}$ The reactivity and structural dynamics of a putative Pd carbide phase remain poorly understood other that it is likely to be less active but more selective than a hydride speciation. ${ }^{30,35-40}$ It is also suggested in the literature that the Pd metal/Pd carbide/Pd hydride structural forms can dynamically interchange in processes driven by the catalytic reaction conditions. ${ }^{30,35-40}$ Recent experimental and theoretical results further show that bound $\mathrm{C}$ atoms, once formed on the catalyst, are preferentially absorbed by (not adsorbed on) the cluster-a preference for the placement of the C-atoms in the subsurface layers of a supported cluster. ${ }^{26,33,40-42}$ The activated absorption of carbon atoms within the metal lattice would presumably yield at its endpoint a palladium carbide phase. The latter species, a metastable phase $\left(\mathrm{PdC}_{\mathrm{x}} ; 0<\mathrm{x} \leq 0.15\right)$ with carbon atoms residing at the interstitial sites of an otherwise face - centered cubic (fcc) Pd lattice, ${ }^{31}$ forms within specific operando conditions of 
hydrogenation processes ${ }^{43}$ In order to better understand the structure-activity relationships that underpin the mechanisms of catalysis a more comprehensive picture of the dynamical attributes of atomic bonding of supported Pd clusters, especially those associated with the metal-carbon interactions that contribute to catalyst speciations in olefin rich environments, will be required.

In this report, we describe the results of a multi-modal operando study of the hydrogenation of ethylene over a silica supported nanoscale Pd catalyst $\left(\mathrm{Pd}_{-} \mathrm{SiO}_{2}\right)$. The work specifically explores the reaction processes that mediate the interconversion of hydride and carbide phases of the Pd clusters, their stability against coarsening, the reversibility of these transformations, and the role that oligomeric products might play in the mechanisms of the selective hydrogenation of $\mathrm{C}_{2} \mathrm{H}_{2}$ in $\mathrm{C}_{2} \mathrm{H}_{4}-\mathrm{a}$ chemistry simplified here via the use of binary ethylene/hydrogen mixtures. The present multi-modal exploration of the atomic structure and chemical state of the $\mathrm{Pd}-\mathrm{SiO}_{2}$ materials exploits a "portable microreactor" that allows combined multi-probe investigations by high resolution transmission electron microscopy (HRTEM), X-ray Absorption Spectroscopy (XAS), and microbeam IR ( $\mu$-IR) analyses under operando conditions (herein catalytic conversions carried out at ambient temperature and $1 \mathrm{~atm}$ pressure of various $\mathrm{H}_{2}$ and ethylene mixtures). ${ }^{44-46}$ These measurements are further correlated with measurements of reaction kinetics and conversion product speciation made by in line Gas Chromatography-Mass Spectrometry (GC-MS). Additional MS measurements were made to characterize hydrocarbon products formed during the reaction that were retained within the reactor via physical interactions with the silica support. The data, when taken together, show a rich interplay of operando structural dynamics that mediate a variety of bond activation $(\mathrm{H}-\mathrm{H}, \mathrm{C}-\mathrm{H}, \mathrm{C}=\mathrm{C})$ and formation $(\mathrm{C}-\mathrm{H}, \mathrm{C}-\mathrm{C}$, $\mathrm{C}=\mathrm{C}, \mathrm{M}-\mathrm{H}, \mathrm{M}-\mathrm{C}$ ) processes. The data notably proscribe the features of predictive compositional and structural models of nanoscale Pd-hydride and Pd-carbide phases formed by the conversion 
of the starting $\mathrm{Pd}-\mathrm{SiO}_{2}$ catalyst on stream and the facility of adsorption processes that subsequently modify and transform them. These dynamic changes illustrate a rich structural and compositional fluxionality that likely influences the chemistries of industrially relevant selective hydrogenation catalysts.

\section{EXPERIMENTAL SECTION}

Two types of reactors were used in the work reported below. These systems have been described in detail in earlier publications. ${ }^{44-45}$ A Clausen cell, a plug-flow reactor, was used for the GC-MS and XAFS measurements. ${ }^{47}$ A multi-modal micro-reactor was used for the $\mu$-IR and TEM measurements. ${ }^{44-45}$ Catalyst samples comprised $~ 1.6 \mathrm{~nm}$ diameter Pd particles supported on $\mathrm{SiO}_{2}$ (Sigma (10-20 nm TEM), 99.5\%), were prepared (1 wt\% loading) and utilized within the catalysis experiments as described in earlier reports. ${ }^{43}$ To minimize heat effects due to the exothermic reaction, the catalyst sample used in the Clausen cell was diluted by a factor of 20 by mixing it with Pd-free silica powder.

GC-MS: An in-line GC-MS system (Agilent 7890A GC equipped with 5975c MS and TCD detector) joined with a GS-GasPro ${ }^{\mathrm{TM}}$ column (Agilent $60 \mathrm{~m}$ by $0.32 \mathrm{~mm}$ ) was used to quantify reaction rates and product identities within effluent stream. The small level of self-hydrogenation activity was specifically monitored via the ethane product. A feed gas flow rate of 20 sccm and the aforementioned Clausen Cell was used in these experiments. The effluent gas was samples after 2 hours for every time the reactor was switched to the next regimes.

Post-reaction MS: Hydrocarbon products retained on the support were extracted for experimental analysis following an extended reaction run at several selected gas compositions (see below). To carry out these analyses, the Clausen cell was flushed with $0.5 \mathrm{~mL}$ of methylene chloride. This liquid was then used to treat the MS probe for analysis. Electron impact (EI) mass 
spectra were measured using a VG 70-VSE mass spectrometer, with the probe temperature held at $60{ }^{\circ} \mathrm{C}$. Catalyst samples were collected after ran at 1 atm gas flow for 2 hours.

TEM: Transmission electron microscopy experiments were conducted using a Titan 80-300 Environmental Transmission Electron Microscope at the Center for Functional Nanomaterials, Brookhaven National Laboratory. Annular dark field scanning transmission electron microscopy images were acquired at a constant image magnification of 640,000 x magnification operating at $300 \mathrm{keV}$. All images were taken after each programmed reaction regime reached a steady state condition after 2 hrs. Multiple STEM images were acquired at each condition.

Micro-IR: IR microspectroscopy experiments were performed using the $\mathrm{N}_{2}$ purged Thermo Nicolet Magna 860 Step-Scan FT-IR and Spectra Tech Continupm IR Microscope at beamline 1.4.4 at the Advanced Light Source, Lawrence Berkeley National Laboratory. The IR spectra were recorded under conditions of continuous gas flow with $4 \mathrm{~cm}^{-1}$ spectroscopic resolution and 256 co-averaged scans.

XAFS: X-ray absorption fine structure data were collected at Beamline 2-2, Stanford Synchrotron Radiation Lightsource, SLAC National Accelerator Laboratory. Measurements were performed in fluorescence mode. The incident X-ray intensity was recorded by using a $15 \mathrm{~cm}$ ionization chamber filled with $100 \%$ Ar and the fluorescence signal monitored by a 13-channel Ge detector. Detailed data processing and fitting procedure are included in SI, page S6.

\section{RESULTS AND DISCUSSION}

The in-situ experiment was performed with a series of reactant gas mixtures (hydrogen/ethylene) of different ratios (10\% increments), as well as additional measurements made under pure hydrogen and ethylene. The "forward sequence" denotes the experiment stage with increasing $\mathrm{C}_{2} \mathrm{H}_{4}$ concentration and the "backward sequence" - the stage with decreasing 
$\mathrm{C}_{2} \mathrm{H}_{4}$ concentration. These ranges were selected to bracket ranges for the mixture of the major components $\left(\mathrm{C}_{2} \mathrm{H}_{4}\right.$ and $\left.\mathrm{H}_{2}\right)$ present in the feed gas of industrial selective hydrogenation processes and further test the reversibility of structural modifications found in operando conditions. The hydrogenation process was carried out at room temperature and 1 atm total pressure with products monitored by MS (using the Clausen cell), or in the microreactor, as described in earlier reports. $^{44}$

As shown in Figure 1, several different products were identified by GC-MS in the effluent stream, ones whose relative concentrations vary with the feed composition. The dominant product formed in all regimes is ethane. We also found a small but appreciable amount of different $\mathrm{C}_{4}$ hydrocarbons in the gaseous product stream that arise as a consequence of the dimerization of ethylene. The latter include butane and 1-butene along with a lesser quantity of butadiene. One notes in these data several interesting trends. The reaction reaches a maximum production of ethane at a hydrogen to ethylene ratio of 1:1 (for this microreactor under the conditions of this experiment this corresponds to $1.4 \% \mathrm{C}_{2} \mathrm{H}_{4}$ converted). As the composition of the feed becomes richer in ethylene, the reaction becomes limited by the hydrogen content. It is interesting to note that the product yield of ethane is not zero when only ethylene is present in the feed. The latter self-hydrogenation reactions (presumably with a correlated production of acetylene) yield a quantity of ethane that is limited to about $1 \%$ of that seen at the maximum conversion conditions $\left(4.7 \times 10^{-6} \mathrm{~mol} / \mathrm{L}\right.$ vs. $2.9 \times 10^{-4} \mathrm{~mol} / \mathrm{L}$ in product). These observations correlate well with the results of past studies reported in the literature. ${ }^{48-50}$ The production of $\mathrm{C}_{4}$ products shows some interesting trends. The production of butane (which at its maximum only reaches levels of about $1 \%$ relative to ethane) reaches a maximum at the essentially the same feed compositions where the ethane yield is maximized. The conversion to this product is most 
efficient in the first cycle and noticeably diminished (poisoned) in the second. The yields of 1butene are notably larger than those of butane and reach maximum production levels at feed compositions with higher ethylene contents. Unlike butane, the activity for its production is essentially unchanged in the replicate cycle. While uniformly low, the processes yielding butadiene appear to be most efficient under conditions where self-hydrogenation predominates.

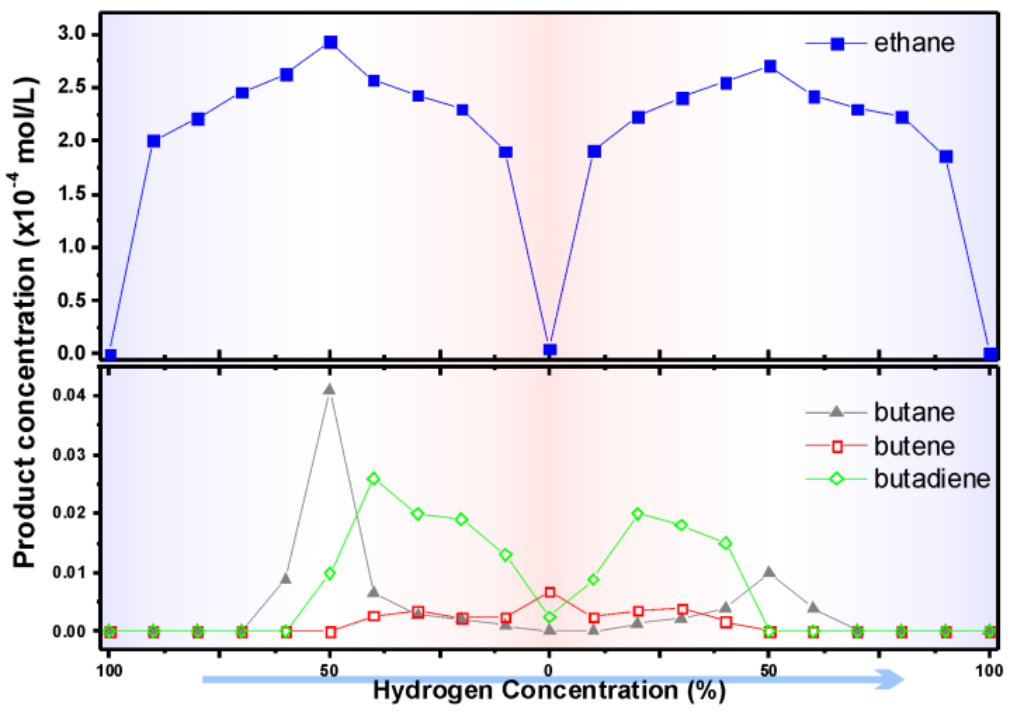

Figure 1. Ethylene conversion in a differential plug-flow microreactor loaded with a $1 \% \mathrm{Pd}-\mathrm{SiO}_{2}$ catalyst in different gas composition regimes monitored by the product concentrations in the effluent gas. The feed gas $\left(\mathrm{H}_{2}\right.$ and $\left.\mathrm{C}_{2} \mathrm{H}_{4}\right)$ composition was gradually switched as specified by the horizontal axis with step size of $10 \%$ for each (the maximum conversion of the ethylene occurs at $1: 1$ composition with a conversion of $1.4 \%$ ethylene).

In previously reported studies of $\mathrm{Pt} / \mathrm{SiO}_{2}$ by correlative use of operando STEM and XAFS, we observed morphological changes of the metal catalyst particles during ethylene hydrogenation reaction. ${ }^{44}$ Intriguingly, STEM images obtained for Pd NPs (Figure 2a with additional data given in Figure S1) in operando conditions for the same reaction regimes show very different trends than was found in the earlier work for Pt. The current data show that the Pd NPs do not undergo 
any significant degree of agglomeration on stream over the full experimental run (Fig. 2b). What is evident, however, is a pronounced broadening of the distribution of Pd cluster sizes relative to the freshly prepared/activated sample. All the same, the mean metal-cluster sizes and their distributions of mass remain in a range where previous studies have established that XAFS data analyses and modeling yield a good description of catalyst structure in the context of a picture of a "representative/average" nanoparticle in the ensemble. ${ }^{44}$ These analyses follow below. 
(a)
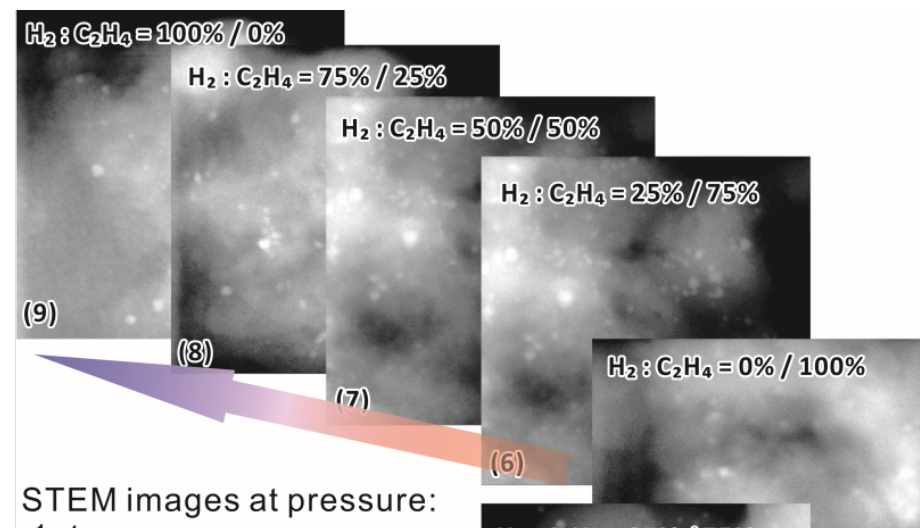
$1 \mathrm{~atm}$
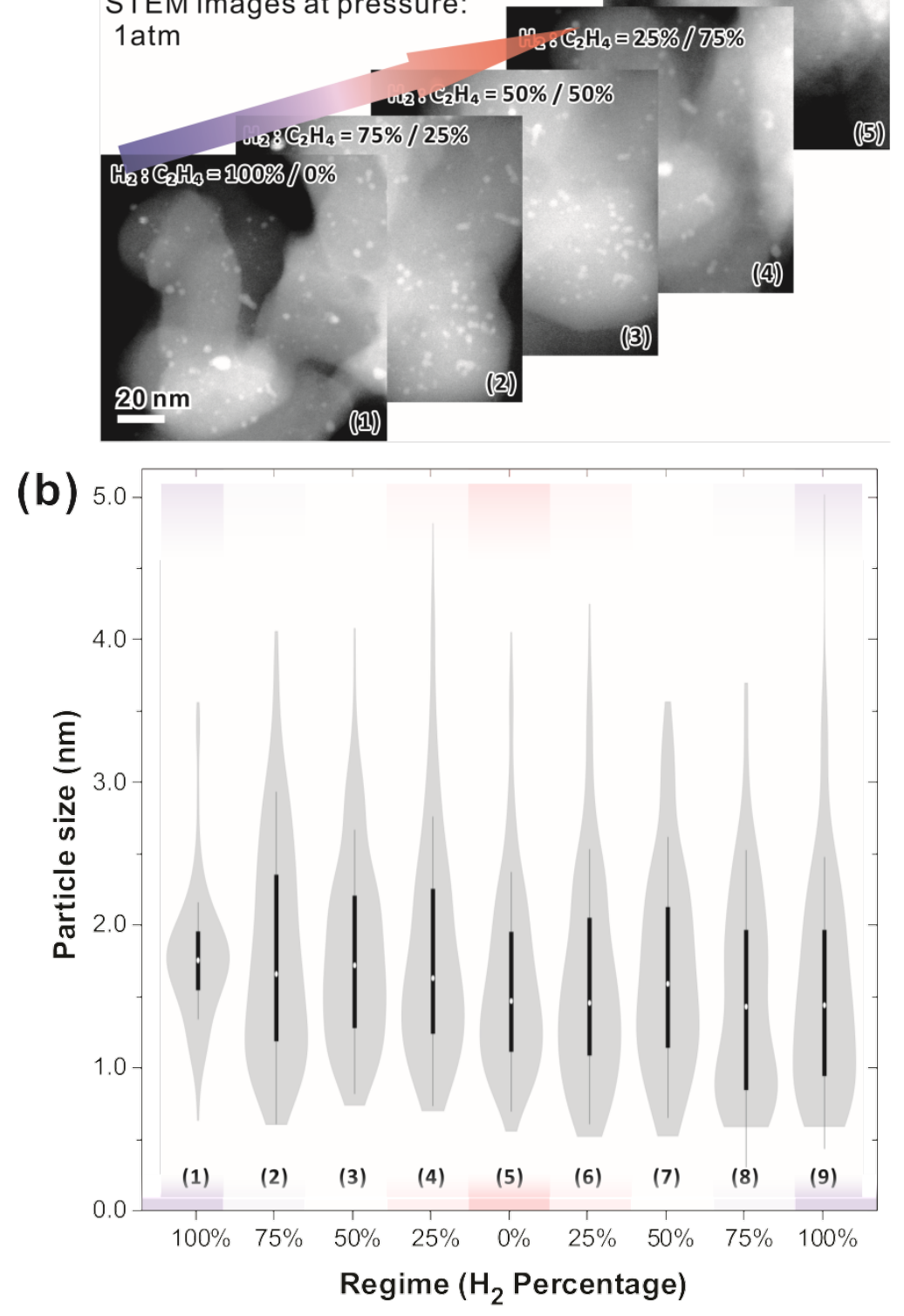

Figure 2. (a) Operando STEM images and (b) STEM measured particle size distributions of Pd NPs supported on $\mathrm{SiO}_{2}$ under different reaction stages at $1 \mathrm{~atm}$. Bold and thin grey lines indicate 
the standard deviation and quartile range respectively. The plots show no statistically significant difference on size distributions.

The Pd K-edge XAFS data provide information about electronic structure and bonding characteristics (coordination numbers, bond lengths and their variances) for Pd atoms and their nearest environments. It is important to note that, due to the large penetration depth of hard Xrays, XAFS spectra are generated from all the Pd sites in the sample. When one is dealing with small nanoparticles, the surface atoms of the nanoparticles contribute much more compared to those in the inner part, as well as changing a lot the mean coordination numbers. It is this feature that makes this technique particularly powerful for analyzing catalysts with metal particle sizes in the range of 1-3 nm in diameter. The current X-ray absorption near edge structure (XANES) data (Figure S2) reveal that clear electronic structural changes are occurring in operando conditions, ones that follow and characterize dynamical features of structure in the different reaction regimes. There is a useful literature to guide the interpretations that follow, ones that track the conversion of metallic Pd clusters through a sequence of hydride and carbide structural transformations and subsequent (and incompletely reversible) reconversion. ${ }^{51-54}$ In the current data, one sees a conversion of the initial state of the XANES as the sample cycles towards a more hydrocarbon rich reactor feed in which the first and second maxima after the edge rise visibly shift (Figure S2). These are behaviors expected for a reaction sequence leading to the production of a Pd carbide phase (where the absorption edge position does not shift as compared to metallic Pd, while the first maximum shifts to higher and the second maximum to lower energy relative to the metallic state). ${ }^{51,} 53,55$ This known behavior can be used therefore as a fingerprint for a specific Pd phase speciation and its conversion in operando conditions. Examining all the spectra taken in the different reaction regimes, we note that those in regimes 1- 
3 (where the feed reaches in sequence a stoichiometric gas feed composition producing the maximum conversion of $\mathrm{C}_{2} \mathrm{H}_{6}, 50: 50$ ), evolve to closely resemble that of a bulk metallic phase. For the data measured in more ethylene rich ambients (regimes 4 and 5), they show, as noted above, the trends associated with a conversion of the Pd to carbide phase. An examination of the spectra collected in the subsequent regimes indicates that this change is not fully reversible under these reaction conditions. For instance, the spectrum collected in pure $\mathrm{H}_{2}$ (regime 9) after the exposure of the catalyst is different from that of the initial sample state formed in this same gas phase ambient. The spectrum collected in regime 9, in fact, more closely resembles that of regime 5 spectrum, although quantitative differences in the first and the second maxima shifts are evidenced (Figure S2).

The Extended X-ray Absorption Fine Structure (EXAFS) data allow a more explicit analysis of the atomistic features of the structural transformations that are implicated within the electronic structure changes discussed above. These data were analyzed using the IFEFFIT software package and FEFF6 program. ${ }^{56}$ The Pd-Pd bond distances and their associated disorder were varied in the fits. Other fitting parameters (coordination number $N$, correction to the photoelectron energy origin $E_{0}$, and amplitude reduction factor $S_{0}{ }^{2}$ ) were constrained for all data sets, which were fit concurrently to minimize correlation effects in the fitting parameters and reduce uncertainties in their best fit values. These constraints are justified by the similarity of the particle distributions seen in the environmental STEM data (Figs. 2 and S1) throughout the sequence of operando reaction conditions. The lack of any shifts of the edge position in the XANES data (Fig. S2) further supports the use of a concurrent fitting protocol that constrains the photoelectron energy origin in the manner described. 
With these assumptions, the analyses yielded useful insights into the bonding habits that were present through the sequence of reaction conditions. The constrained fits are summarized in Table S1 with typical spectra plotted in Figure S3, yield a value for the first shell Pd-Pd coordination number of $8.1 \pm 0.3$. This is a value suggesting a mean particle size of about $1.6 \mathrm{~nm}$ (containing about $92 \mathrm{Pd}$ atoms), assuming a truncated cuboctahedral cluster shape that accords well with both the morphologies and particle size distribution data measured by STEM (Fig. 2) ${ }^{44}$ The latter assessment follows from a geometric model of a truncated cuboctahedral cluster made using the experimentally determined bonding parameters from the EXAFS data analyses in conjunction with Equation (1): ${ }^{44}$

$$
N=\frac{2 m(d)}{n(d)}=\frac{60\left(\frac{d}{r}\right)^{3}+126\left(\frac{d}{r}\right)^{2}+84\left(\frac{d}{r}\right)}{5\left(\frac{d}{r}\right)^{3}+24\left(\frac{d}{r}\right)^{2}+40\left(\frac{d}{r}\right)+24}
$$

where $N$ is the coordination number of nearest neighbors to $\mathrm{X}$-ray absorbing atoms, $m$ is the total number of nearest neighbor pairs, $n$ is the total number of atoms, $r$ is the first nearest neighbor distance $(\approx 2.745 \AA$ as obtained from the inferred metal-like state of Regime 3$)$, and $d$ is the deduced size of the cluster.

Table 1. Exemplary Corresponding Particle size (d) of Given Numerical Pd-Pd Coordination Numbers $(N)$

\begin{tabular}{ll}
\hline$N$ & $d(\mathrm{~nm})$ \\
\hline 4.8 & 0.549 \\
7.0 & 1.098 \\
8.2 & $1.647^{*}$ \\
8.9 & 2.196 \\
\hline
\end{tabular}

* The particle size of this specific sample obtained from STEM measurements ( $\left.d_{\text {STEM }}\right)$ is 1.7 $\mathrm{nm}$. 
As the Table 1 shows, particle dimensions in this size range (where Pd occupation of low coordination surface sites is statistically very important) scale strongly with the average coordination number of nearest neighbor Pd-Pd bonds, a feature strongly reinforcing the assessments coming from the E-STEM data.
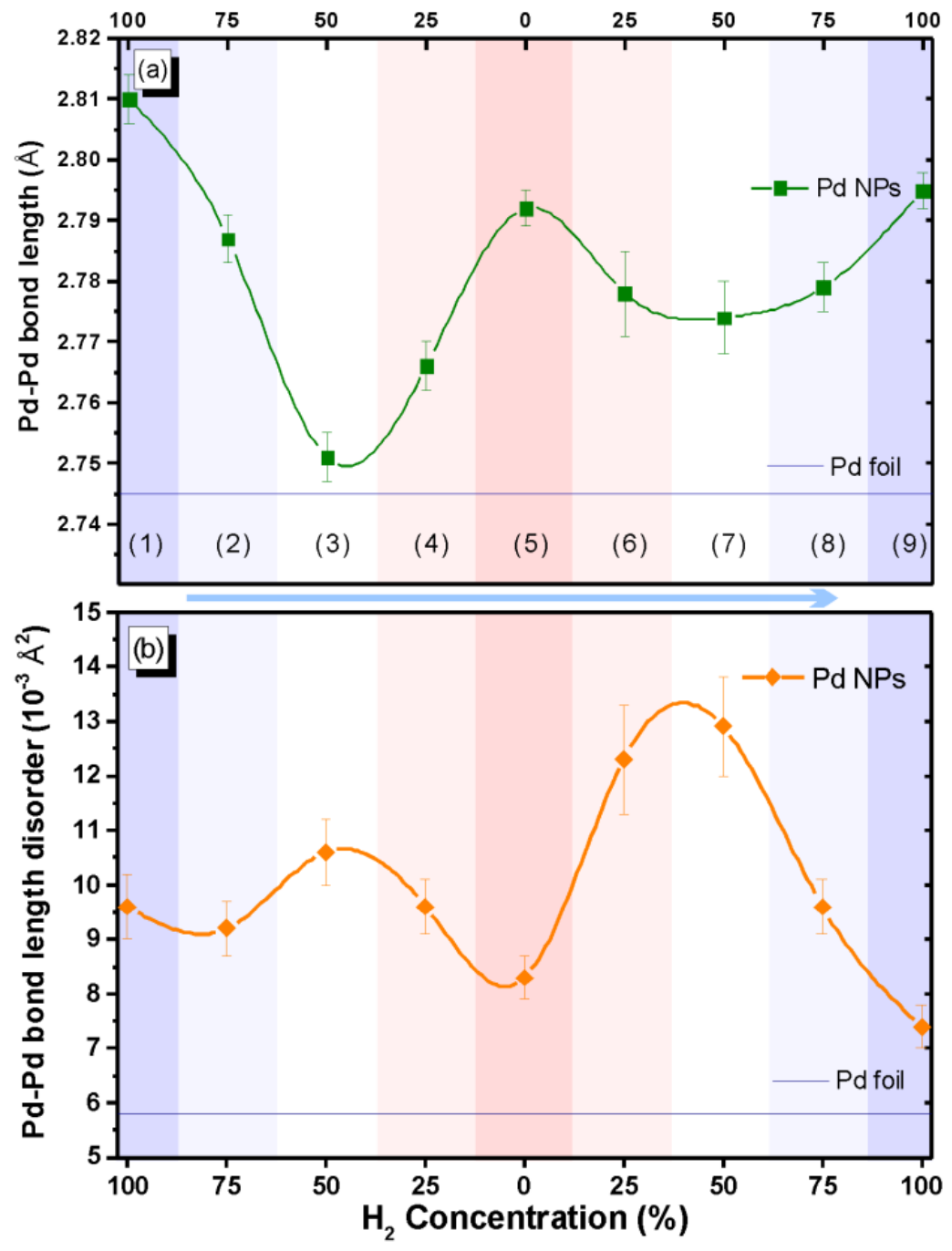

Figure 3. EXAFS analysis results of (a) the interatomic distances $r$ and (b) bond length disorder $\left(\sigma^{2}\right)$ for $\mathrm{Pd}_{-} \mathrm{SiO}_{2}$ catalyst under different feed gas composition regimes of $\mathrm{H}_{2}$ and $\mathrm{C}_{2} \mathrm{H}_{4}$ (from 
pure $\mathrm{H}_{2}$ to pure $\mathrm{C}_{2} \mathrm{H}_{4}$ and then back to pure $\mathrm{H}_{2}$ ). The dashed line in (a) indicates the bond length of bulk Pd (foil).

We now turn to a more detailed consideration (beyond average metal cluster size) of the atomic bonding that is present in active catalytic clusters and the nature of the chemical transformations they might be experiencing. The data presented in Figure 3 illustrate that strong sensitivities to reaction conditions operate in this system, with substantial modifications of the bonding being evidenced (e.g. large, and apparently hysteretic bond relaxations) as the feed gas compositions are varied through the sequence of regimes outlined in Figure 1. One remarkable observation evident from comparing the top and bottom panes in Figure 3, where the dependences of the values for the Pd-Pd bond lengths and bond length disorder parameters are plotted, is that they qualitatively appear to be mirror images of each other. Specific and substantive chemical modifications of the Pd clusters underpin these trends. In the discussions that follow, we explain both of these effects, as well as the trends described in the XANES data, in the context of the aforementioned chemical model of the structural and electronic transformations manifested during the catalysis. First, we note that the Pd-Pd bond length in Regime 3 (the point of maximum conversion reached with 1:1 ratio of $\mathrm{H}_{2}$ and $\mathrm{C}_{2} \mathrm{H}_{4}$ ) is very close to that of bulk, metallic Pd $\left(d_{0}=2.745 \AA\right.$ ). This further supports and extends the structural inferences developed from the XANES data (Figure S2). It follows as a result, that both the bonding and electronic structural effects observed in these measurements report on the development of a generally metal-like structure for the Pd NPs in that regime. The increase in the bond length disorder in this case is correlated with a state of highest activity for the hydrogenation reaction. An intriguing hypothesis is one that associates this impact with the nature of the adsorbate bonding present on the surface of NPs in that regime, that it is patterns of 
bond strains developed in consequence that increase bond disorder as the regimes are traversed. These effects are even more pronounced in the vicinity of the next local activity maximum associated with regime 7. It is also seen that the Pd-Pd bond length is again minimized here, relative to the significant strains seen in the neighboring pure gas limits (regimes 5 and 9). The structure in this case, must retain a form of perturbation as it never recovers the metal-like bond length seen in regime 3. The picture that arises for the latter, then, is one of a set of essentially bulk-like bonding in the core of the silica-supported Pd clusters joined with adsorbate-mediated structural relaxations at their surfaces. The bond strains seen for their precursor state (regime 1) have a well understood, and as we will show quantitatively verifiable, origin (vide infra).

The Pd-Pd bond lengths in pure $\mathrm{H}_{2}$ (regimes 1 and 9) and in pure $\mathrm{C}_{2} \mathrm{H}_{4}$ (regime 5) are longer than those of regimes 3 and 7. They also correspondingly appear to be more ordered. Despite these similarities, the corresponding Pd NP structures in each case are quite different. Specifically, the larger Pd-Pd bond distance in the initial pure hydrogen regime points towards the formation of a Pd beta-hydride phase. ${ }^{44}$ In that phase, hydrogen atoms occupy random interstitial octahedral sites in Pd fcc structure, causing an expansion but with no change in Pd lattice symmetry. This correlates well with the fact that no changes are seen in the average size of Pd nanoparticles in consequence of the change in the feed composition. The magnitude of bond length expansion seen under hydrogen depends critically on the $\mathrm{H}$ occupancy and, due to finite truncations, on the Pd cluster size. As a result, the bond strain in this case provides a means that can be used to determine the Pd NP size. ${ }^{44,57}$

An empirical, but now well validated model, allows a correlation to be made between the average first shell-Pd-Pd bond length and the composition $\left(\mathrm{PdH}_{\mathrm{x}}\right.$, where $\left.\mathrm{x}<1\right)$ of the beta hydride phase. ${ }^{43-44,57}$ This correlation is shown in the plots given in Figure S4. This provides, then, an 
explicit means to calculate the $\mathrm{H}$ intercalation $(\mathrm{H} / \mathrm{Pd})$ ratio for the supported nanoscale $\mathrm{Pd}-$ Ohydride clusters present in regime 1 using the experimentally measured Pd-Pd bond length. These data suggest a stoichiometry lying in a narrow range centered on $x=0.40$. This value can be evaluated within a geometric model to infer an average particle diameter, examining how the finite truncation of a specific cluster shape and size would impact the number density of octahedral sites (those occupied by $\mathrm{H}$ in the beta hydride phase). The results of this analysis, following a previously reported method, are presented in Figure $4{ }^{44}$. Here the cluster sizes were progressively incremented and the inferred $\mathrm{H} / \mathrm{Pd}$ ratio deduced from the octahedral site densities lying within model closed-shell truncated cuboctahedral clusters. The experimentally determined value of the Pd-Pd bond length (Fig. 3) can be used to provide a stoichiometry for the hydride phase based on the relationship plotted in Fig.S4. The composition so deduced is shown in Figure 4 together with its error bars projected to a set of $\mathrm{x}$-axis intercepts (cluster size) taken from the STEM data analysis of the cluster size distribution (Fig. 2b). One sees that, even given the qualitative features guiding it, the intercalation model (Figure 4) predicts a geometric habit the Pd clusters that is bounded by model 37 and 92 atom truncated cube octahedral clusters, a motif that is remarkably similar to the assessments made from the EXAFS and E-STEM data discussed above. As Figure 4 illustrates, average particle size in this ranges afford a good description of the maximum bond strains seen in the hydride phase based solely on a consequence of how the finite crystal truncations scale the approximate density of octahedral sites as a fraction of the total number of metal atoms present in the fcc structure. This establishes a possible testable prediction for theory that the bond length expansion is in fact one limited by the approximately $50 \%$ ratio of $\mathrm{H}$ to Pd (i.e., the full occupancy in a particle of this size) in an otherwise unperturbed beta hydride structure. ${ }^{44}$ 
A similar peculiar behavior in the Pd-Pd bond lengths and their associated disorder is seen in pure ethylene (regime 5, Fig. 3). The perturbations in this case are not caused by hydrogen intercalation, as any such absorbed $\mathrm{H}$ atoms are known to be readily consumed by the hydrogenation reaction(s) under the latter conditions. The lattice expansion must result from a different cause, likely by carbon insertion into the Pd structure, as suggested most notably by the XANES data discussed above (vide supra). There is striking similarity between the structures adopted by Pd upon uptake of either carbon and hydrogen atoms, specifically: 1) both occupy octahedral sites in the Pd fcc structure; and 2) neither causes restructuring of Pd lattice beyond tensile bond strains that expand it from its bulk value. As a result, the Pd-Pd coordination numbers are not affected by either intercalation mechanism, which is justified by the size measurements by STEM. Since carbon atoms are larger and also provide more valence electrons than hydrogen, their interstitial occupancy in Pd lattice is significantly lower. The current literature suggests that the likely structure of $\mathrm{Pd}$ carbide is one comprising a $\mathrm{Pd}_{6} \mathrm{C}$ composition. In the latter, theoretical calculations suggest the adoption of a fcc Pd lattice in which the absorbed carbon occupy $\sqrt{3} \times \sqrt{3}$ sites between every two (111) Pd planes with another layer of vacant sites-this structures is energetically favored among all possible Pd-C stoichiometries. ${ }^{32}$ The finite crystal truncations of the nanoscale Pd clusters should affect the C/Pd ratio in a carbide phase forming under operando conditions in a manner analogous to that described above for the hydride structure. The result is that stoichiometry for $\mathrm{C}$ must be less than that in the $\mathrm{Pd}_{6} \mathrm{C}$ bulk phase (because some subsurface sites are not available for $\mathrm{C}$ insertion), and this in turn must affect the magnitude of the tensile strains evidenced in the Pd-Pd distances. ${ }^{32}$ It is therefore possible to use the experimental Pd-Pd distance to infer both a stoichiometry for the carbide in the operando context as well as a confirming average particle size in a manner similar to what 
was done for the nanoscale Pd hydrides discussed above. ${ }^{44}$ To do so, we in turn: 1 ) deduced a stoichiometry for the Pd-carbide based on the experimental Pd-Pd bond length (Fig. 3) using the compositional scaling formalism presented in Fig. S4; and 2) estimated a size for the Pd clusters based on finite cluster truncations that yield a C/Pd ratio with that embedded bond strain. We employed for lack of a better theoretical model a linear relationship between the C/Pd ratio and the known limiting Pd-Pd bond lengths, an approximation justified by the Pd-Pd bond length variation between the metallic Pd and bulk $\mathrm{Pd}_{6} \mathrm{C}$ phases (Figure S4 b). The lower part of Figure 4 shows the correlation between the cluster size distribution determined from the E-STEM data and the correlated C/Pd stoichiometry deduced from the experimental bond strain. An exemplary Pd carbide cluster coming from this model is shown schematically as an inset. We see here that the analysis of cluster size derived from the strain-based intercalation model is in strong accord with the assessments made by both EXAFS and direct E-STEM measurements (where again the deduced structures falls very close to the bounding limit afforded by 92 atom closed-shell truncated cuboctahedral clusters (with the $\mathrm{C} / \mathrm{Pd}$ ratio of $8.3 \%$, corresponding to an average particle size of $\sim 1.8 \mathrm{~nm}$, Fig. 4). This result agrees very well with STEM observations, the previously estimated Pd particle size from $\mathrm{H}$ intercalation results (vide supra), and the XAFSdetermined Pd NP size (1.6 nm), estimated from the measured Pd-Pd coordination numbers. This strongly suggests that the speciation inferred in this model must capture this feature of the structure in-operando in a qualitatively (and possibly quantitatively) predictive way. 


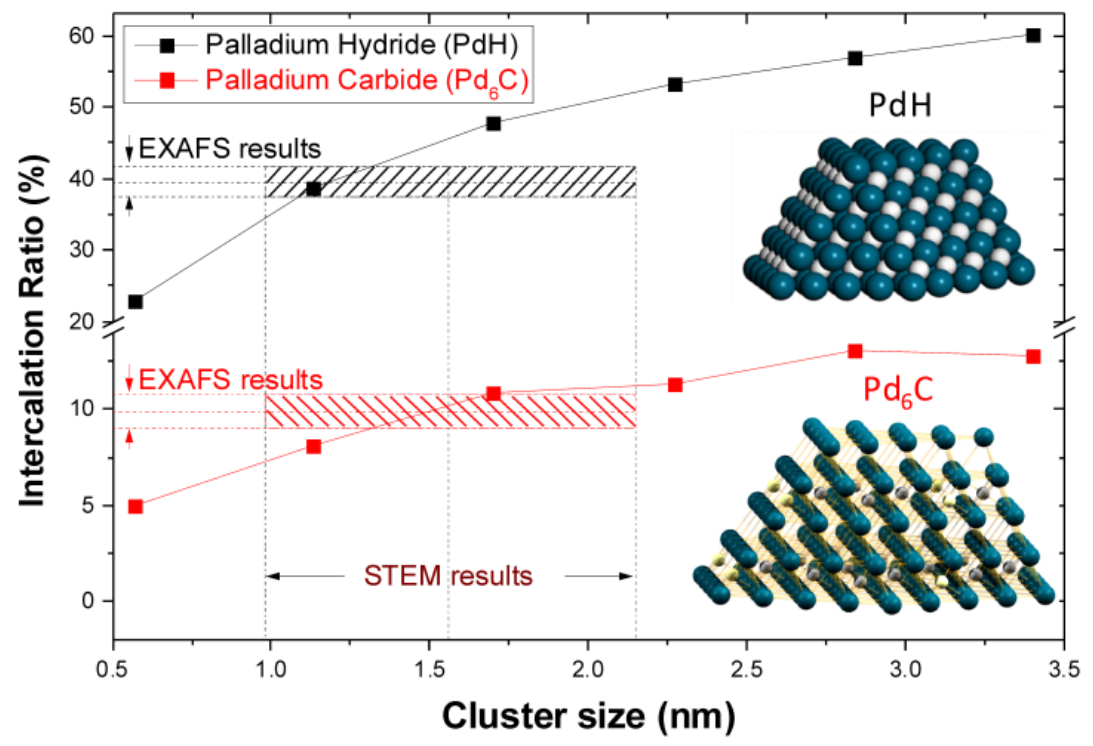

Figure 4. Correlation between the $\mathrm{Pd}$ nanoparticle size, and the intercalation ratio (H/Pd or C/Pd). Shaded area shows the experimentally obtained ratio, as calculated from the measured PdPd distance. The curves and symbols correspond to the theoretically calculated ratios, assuming the full $\mathrm{H}$ or $\mathrm{C}$ occupancy and a hemispherical cuboctahedral model, for different particle sizes. The range of sizes that correspond to the shaded areas was chosen to agree with the experimentally measured (STEM) size distribution. The overlap of the model curves with the shaded areas validates both (the nano-hydride and nano-carbide) models.

We note also that formation of stoichiometric (or almost stoichiometric, as shown here) hydride and carbide structures, coupled to the lack of (or very low) catalytic activity in conditions of pure hydrogen or ethylene (save for self-hydrogenation, see below), respectively, may help explain the relative decrease in structural disorder seen in regimes 1,5 and 9,as compared to the high conversion activity cases (regimes 3 and 7), where in the latter enhanced structural disorder might be expected in consequence of complex adsorbate mediated dynamics at the catalyst's surface. 
In summary, our combined examinations of the morphological (Figure 2), electronic (Figure S2) and structural (Figure 3) characteristics of Pd NPs reveal dynamic transformations between Pd hydride, metal and carbide structures as are induced by changes made in the operando reaction conditions. These data illustrate a facile conversion of a Pd-hydride phase to a metastable carbide as the gas phase ambient becomes olefin rich. It's reversion, however, is not completely efficient. This is perhaps more clearly evidenced by the overall trends of the data shown in Figure 3, most notably in the very different magnitudes of Pd-Pd bond length strains and disorder seen in gas composition regimes 3 and 7 -features that also correlate with the somewhat less efficient conversions of ethylene to ethane seen in the latter (Figure 1). Guided by these observations and by the XANES results discussed above, we propose that the carbon atoms forming the carbide are likely retained in the Pd lattice, frustrating reconversion to a pure hydride phase on return full sequence to the hydrogen rich ambient. In the latter regime, this carbide phase would only persist due to kinetic limitations of the necessary $\mathrm{H}_{2}$ coupled regenerative reactions that would remove it (as do occur at higher temperatures).

The source of the $\mathrm{C}$ that forms the carbide phase must arise as a consequence of dissociative pathways that lead to the cleavage of C-C bonds of some type. What these pathways might be are not fully understood, at present, although some inferences can be made on the basis of other minor products that are found in the process stream. We have found, for example, that very low levels of production to $\mathrm{C}_{3}$ species (propane and propene) are also seen (Figure S5), with activities that seem well correlated with production of the $\mathrm{C}_{4}$ products discussed above. The other correlated activity, as relevant to the one regime most explicitly, is in pure ethylene where self-hydrogenation at low rate levels is noted. The acetylene that must be coproduced in this instance likely will be subject to further conversion via dissociative pathways. ${ }^{50}$ 


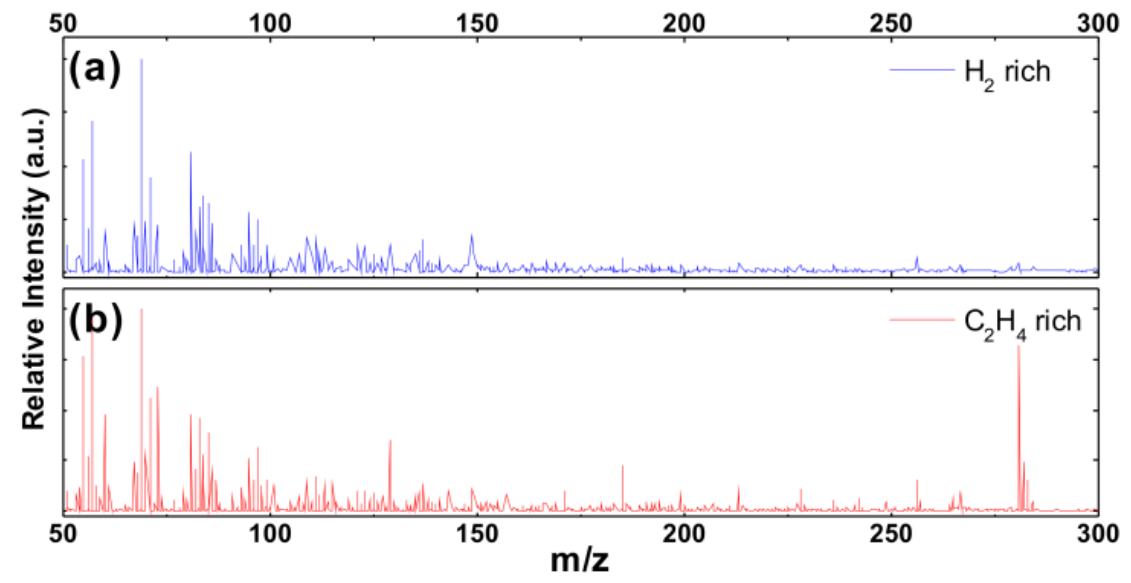

Figure 5. Surface extracted (ex-situ) mass spectra of residue species on catalyst collected from the ethylene hydrogenation reaction with different feed gas composition: (a) $75 \% \mathrm{H}_{2}+25 \% \mathrm{C}_{2} \mathrm{H}_{4}$ ( $\mathrm{H}_{2}$ rich, regime 2) and (b) $25 \% \mathrm{H}_{2}+75 \% \mathrm{C}_{2} \mathrm{H}_{4}\left(\mathrm{C}_{2} \mathrm{H}_{4}\right.$ rich, regime 4).

The data presented above illustrate an exemplary case where the reactions are mediated by a dynamical catalyst system whose structure and chemical speciation arises as a direct consequence of the operando conditions associated with its use. The chemistry described above, processes that mediate the conversion of a Pd-hydride to a carbide phase, are ones that change the electronic and atomic structure of the catalysts in significant ways. We infer as well that the kinetic stability of the carbide phase could lead to impacts on the catalysts activity that correlates with that feature. As noted above, the hydride state is the most efficient catalyst for the formation of ethane (Figure 1). This aspect of activity is also mirrored in the oligomerization processes that afford $\mathrm{C}_{4}$ hydrocarbons. One notes, though, that these same data show that the production of the oligomeric alkene and polyene products are little affected by the conversion to the carbide form. We cannot, at present, fully account for this observation except to note that the products in these instances likely involve beta-hydride elimination mechanisms of surface alkyls (for butane) to 
form the final product (a step that generates surface bound hydrogen). Alkanes, on the other hand, can only arise as a consequence of formal reductive elimination processes that generate the last formed C-H bond of the product.

The literature suggests that the oligomerization we see might in fact lead to other products than those discussed above. We examined, for this reason, that state of the catalyst samples both in operando conditions, using $\mu$-IR methods as well as by a final post mortem analysis that characterized by MS any oligomerization products that could be extracted from the support after the end of a run. The latter qualitative MS analyses were made for samples that had been held in either $\mathrm{H}_{2}$ or $\mathrm{C}_{2} \mathrm{H}_{4}$ rich regimes (2 and 4) prior to isolation and extraction. These studies confirmed the formation of heavier hydrocarbon species in each of these cases. As Figure 5 shows, the species extracted from the catalyst support are fairly complex, with the coexistence of different structures with various degrees of unsaturation. In both cases, several prominent peaks can be discerned in the spectra, corresponding to $\mathrm{C}_{4}-\mathrm{C}_{8}$ fragments (see Table S2 for the list of peaks). For the $\mathrm{H}_{2}$ rich regime, the largest MW hydrocarbon observed had a chain length of about $\mathrm{C}_{10}$ to $\mathrm{C}_{12}$. Molecules of this size can be still regarded as slightly volatile, though the boiling point may be higher than $100^{\circ} \mathrm{C}$ and for this reason are expected to accumulate on the silica support. In comparison, the products collected under the $\mathrm{C}_{2} \mathrm{H}_{4}$ rich regime contain much larger molecules, with fragments for chain lengths up to $\mathrm{C}_{20}$ being observable in the data; aliphatic hydrocarbons of this size have a very low vapor pressure and would also be strongly retained within the silica support materials. The electron impact ionization fragmentation patterns seen in these data cannot be rationalized by assignment to a single product. We have made tentative assignments to the fragments that highlight important masses and their composition. It seems, based on qualitative assessments that the molecules formed in the $\mathrm{C}_{2} \mathrm{H}_{4}$ 
rich regime must minimally contain a complex mixture of varied chain length alkanes and alkenes. That their formation appears to have little sensitivity to the state of the catalyst, may in fact be misleading, given that the production of alkenes and polyenes becomes most pronounced as the feed composition is advanced to the ethylene rich regime, and thereafter follows a rate sensitivity associated with the carbide phase.

We performed additional $\mu$-IR spectroscopy studies to better examine the production of the oligomeric hydrocarbons in operando conditions, varying gas phase compositions within the microreactor in the manner described. The data presented in Figure 6 show exemplary spectra taken for a catalyst sample that had been cycled through the range of compositions and then stepped and held for 2 hours at each regime in the same sequence for ethylene hydrogenation, and recording infrared spectra for each. All the spectra show characteristic modes in the C-H stretching region, ones whose lineshapes and intensities vary markedly as the gas phase composition is varied. The three peaks centered roughly at 2958, 2922 and $2850 \mathrm{~cm}^{-1}$, assignable to various modes of methylene and methyl groups, strongly suggest the present on the support of aliphatic species under in operando conditions. These assignments follow those for the C-H stretching modes of model linear hydrocarbons. ${ }^{58}$ 


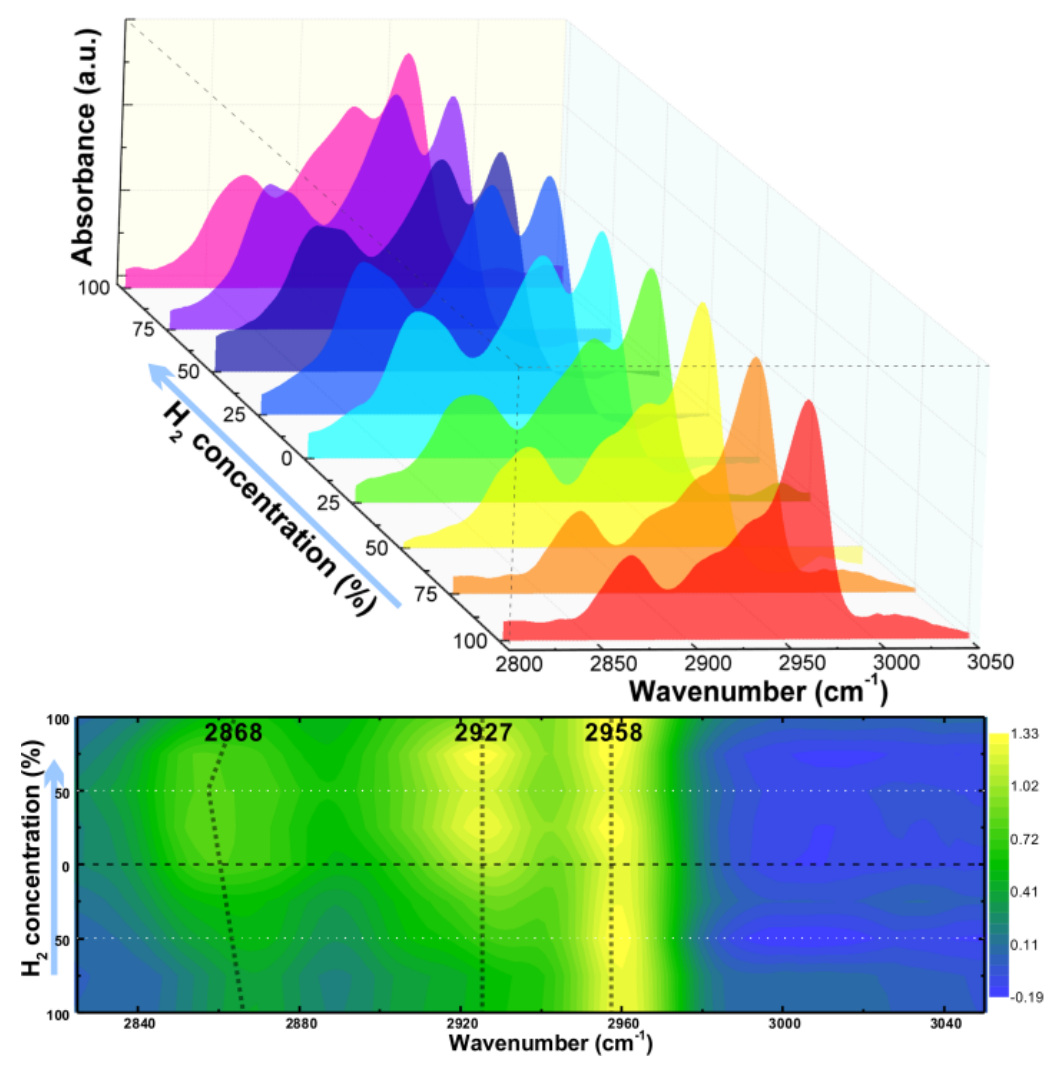

Figure 6. IR spectra collected in operando conditions under different regimes of feed gas concentration for room temperature ethylene hydrogenation over $\mathrm{Pd}-\mathrm{SiO}_{2}$ catalysts. Top waterfall figure show individual spectra acquired under different regimes, the lower contour map highlights the maxima of hydrocarbon fingerprint bands. Note that there was some exogenous hydrocarbon background from the very beginning, so that $2958 \mathrm{~cm}^{-1}$ band is not taken as a benchmark.

The data show a further complexity in positions of the modes during the cycling of the catalyst, notably the shifting of the broad band at $2868 \mathrm{~cm}^{-1}$ to lower energies as the catalyst enters the ethylene rich regime and is then progressively returned to a hydrogen rich ambient. These data can be interpreted in terms of the impact of the unsaturation within the hydrocarbon chain, and its impact on the $\mathrm{CH}_{2}$ symmetric stretching vibration of methylene groups proximal to 
it. The tentative model we propose is one of chain growth within the hydrogen rich regimes leads to a variety of unsaturated hydrocarbons, including linear $\alpha$-olefins (LAOs), an assignment supported by the off line MS data. ${ }^{59}$ One problem we note is that the expected modes for the olefinic C-H bonds are not in evidence in these data. As these modes are typically much weaker than those of the aliphatic substituents in long chain hydrocarbons, the present data quality does not allow their unambiguous exclusion. The other complex feature, namely the redshift mentioned above, could be associated with perturbations due to the adsorption of the hydrocarbon species on the surface of the Pd (and silica) particles. Alternatively, we believe the impacts may be due to hydrogenation activities, that the passage of the feed through a hydrogenpoor regime leads to the buildup of unsaturated, as well as polyunsaturated, long chain hydrocarbons on the support. As $\mathrm{H}_{2}$ rich conditions are restored, these unsaturated hydrocarbons should be mobile enough on the support to allow them to be hydrogenated and thus over time tip the limiting composition towards that of linear alkanes that remain physisorbed on the support.

\section{CONCLUSION}

The results of a multi-modal, operando investigation of the structural dynamics of a silicasupported Pd catalyst reveals that the reaction conditions drive pronounced composition coupled structural transformations during the hydrogenation of ethylene. Under hydrogen rich conditions, the active nanoscale catalyst metal clusters exist in the form of a beta-hydride phase, one whose composition is determined (relative to the $1: 1 \mathrm{Pd} / \mathrm{H}$ ratio found in a bulk phase) by finite crystal truncations that limit hydride occupancies at octahedral sites. Transformation to a carbide phase in an olefin rich ambient proceeds via the intermediacy of a metallic phase from which the hydride atoms are removed and is subsequently transformed by complex dissociative pathways producing the $\mathrm{C}$ atoms that are absorbed within the Pd. The stoichiometry of the supported Pd- 
carbide clusters formed in this operando regime is also limited (from a value of $\mathrm{Pd}_{6} \mathrm{C}$ in the bulk) by its finite truncation of crystal in consequence of the restrictions that feature imposes on the necessary octahedral sites needed for its uptake. The latter conversion is hysteretic and not fully reversible on return to a hydrogen-rich gas feed. The complex dynamic electronic and structural properties seen in this exemplary catalyst makes important suggestions about the speciation and structure of the active Pd catalysts that mediate the selective hydrogenation of acetylene in a predominate ethylene gas feed, a critical process required to purify upstream feeds for polyolefin processes. The data further illustrate a strongly conserved activity for the oligomerization of the ethylene in the feed, a reactivity that is able in the olefin-rich ambient to generate unsaturated oligomeric materials with carbon chain lengths reaching as high as C20. These low volatility hydrocarbons accumulate on the support during the time on stream and appear to be susceptible to further hydrogenation-based transformations themselves. Taken together, Pd appears to foster a unique activity towards absorbtive uptake of both $\mathrm{H}$ and $\mathrm{C}$ atoms as a consequence of this otherwise simple catalytic transformation. The most striking observation coming in this work is relative structure insensitivity of the oligomerization processes that operate as a minor side reaction, an activity seen to operate in operando regimes where hydrogenation pathways are most efficient due to their mediation by various hydride and/or metallic states of the Pd, as well as in those where dissociative pathways lead to the formation of a nanoscale carbide phase. An important point that future work might address is to explore whether specific forms of alloying, as are present in industrially important selective hydrogenation catalysts, can in fact usefully modulate this latter activity. ASSOCIATED CONTENT 
Supporting Information. Additional facts related to the results and analysis of the STEM and XAFS experiments, as well as more GC-MS and surface MS results are included. This DOC file is available free of charge via the Internet at http://pubs.acs.org

\section{AUTHOR INFORMATION}

\section{Corresponding Author}

*frenkel@bnl.gov

*estach@bnl.gov

*r-nuzzo@illinois.edu.

\section{Author Contributions}

$\perp$ These authors contributed equally.

\section{Notes}

The authors declare no competing financial interests.

\section{ACKNOWLEDGMENT}

The authors gratefully acknowledge support for this by the US Department of Energy, Office of Basic Energy Sciences under Grant No. DE-FG02-03ER15476. AIF acknowledges support of the Program Development Fund at Brookhaven National Laboratory. The development of the micro-cell was supported, in part, by an LDRD grant at Brookhaven National Laboratory. We acknowledge the facilities support provided at the Center for Functional Nanomaterials, the National Synchrotron Light Source at the Brookhaven National Laboratory (US Department of Energy, Office of Basic Energy Sciences, Contract No. DE-SC0012704) and the Synchrotron 
Catalysis Consortium (US Department of Energy, Office of Basic Energy Sciences, Grant No. DE-SC0012335).

\section{REFERENCES}

(1) Corma, A.; Iborra, S.; Velty, A. Chemical routes for the transformation of biomass into chemicals. Chem. Rev. 2007, 107, 2411-2502.

(2) Blaser, H. U.; Malan, C.; Pugin, B.; Spindler, F.; Steiner, H.; Studer, M. Selective hydrogenation for fine chemicals: Recent trends and new developments. Adv. Synth. Catal. 2003, 345, 103-151.

(3) Bond, G. C.; Wells, P. B. The Mechanism of the Hydrogenation of unsaturated hydrocarbons on transition metal catalysts. Adv. Catal. 1964, 15, 91-226.

(4) Bond, G. C.; Sheridan, J. Studies in heterogeneous catalysis .2. the hydrogenation of allene. Trans. Faraday Soc. 1952, 48, 658-663.

(5) Bond, G. C.; Phillipson, J. J.; Wells, P. B.; Winterbottom, J. M. Hydrogenation of olefins Part.1 Hydrogenation of ethylene, propylene and the N-butenes over alumina-supported platinum and iridium. Trans. Faraday Soc. 1964, 60, 1847-1864.

(6) Zaera, F.; Somorjai, G. A. Hydrogenation of ethylene over platinum(111) single-crystal surfaces. J. Am. Chem. Soc. 1984, 106, 2288-2293.

(7) Teschner, D.; Vass, E.; Havecker, M.; Zafeiratos, S.; Schnorch, P.; Sauer, H.; KnopGericke, A.; Schloegl, R.; Chamam, M.; Wootsch, A.; et al. Alkyne hydrogenation over Pd catalysts: A new paradigm. J. Catal. 2006, 242, 26-37.

(8) Cremer, P. S.; Somorjai, G. A. Surface science and catalysis of ethylene hydrogenation. J. Chem. Soc., Faraday Trans. 1995, 91, 3671-3677. 
(9) Delacruz, C.; Sheppard, N. The infrared-spectrum from hydrogenation of the surface species from ethene chemisorbed on a $\mathrm{Pt} / \mathrm{SiO}_{2}$ catalysts - the surface ethyl group. J. Mol. Struct. 1991, 247, 25-30.

(10) Briggs, D.; Dewing, J.; Burden, A. G.; Moyes, R. B.; Wells, P. B. Support effects in ethene hydrogenation catalyzed by platinum. J. Catal. 1980, 65, 31-35.

(11) Binder, A.; Seipenbusch, M.; Muhler, M.; Kasper, G. Kinetics and particle size effects in ethene hydrogenation over supported palladium catalysts at atmospheric pressure. J. Catal. 2009, 268, 150-155.

(12) Pecoraro, T. A.; Chianelli, R. R. Hydrodesulfurization catalysis by transition metal sulfides. J. Catal. 1981, 67, 430-445.

(13) Borodziński, A.; Bond, G. C. Selective Hydrogenation of ethyne in ethene- rich streams on palladium catalysts. Part 1 . Effect of changes to the catalyst during reaction. Catal. Rev. 2006, $48,91-144$.

(14) Borodziński, A.; Bond, G. C. Selective hydrogenation of ethyne in ethene- rich streams on palladium catalysts, Part 2: Steady- state kinetics and effects of palladium particle size, carbon monoxide, and promoters. Catal. Rev. 2008, 50, 379-469.

(15) Zhang, Q.; Li, J.; Liu, X.; Zhu, Q. Synergetic effect of Pd and Ag dispersed on $\mathrm{Al}_{2} \mathrm{O}_{3}$ in the selective hydrogenation of acetylene. Appl. Catal., A 2000, 197, 221-228.

(16) Zea, H.; Lester, K.; Datye, A. K.; Rightor, E.; Gulotty, R.; Waterman, W.; Smith, M. The influence of $\mathrm{Pd}-\mathrm{Ag}$ catalyst restructuring on the activation energy for ethylene hydrogenation in ethylene-acetylene mixtures. Appl. Catal., A 2005, 282, 237-245.

(17) Khan, N. A.; Uhl, A.; Shaikhutdinov, S.; Freund, H. J. Alumina supported model Pd-Ag catalysts: A combined STM, XPS, TPD and IRAS study. Surf. Sci. 2006, 600, 1849-1853. 
(18) Huang, W.; McCormick, J. R.; Lobo, R. F.; Chen, J. G. Selective hydrogenation of acetylene in the presence of ethylene on zeolite-supported bimetallic catalysts. J. Catal. 2007, $246,40-51$.

(19) McCue, A. J.; Anderson, J. A. Recent advances in selective acetylene hydrogenation using palladium containing catalysts. Front. Chem. Sci. Eng. 2015, 9, 142-153.

(20) Osswald, J.; Giedigkeit, R.; Jentoft, R. E.; Armbrüster, M.; Girgsdies, F.; Kovnir, K.; Ressler, T.; Grin, Y.; Schlögl, R. Palladium-gallium intermetallic compounds for the selective hydrogenation of acetylene: Part I: Preparation and structural investigation under reaction conditions. J. Catal. 2008, 258, 210-218.

(21) Studt, F.; Abild-Pedersen, F.; Bligaard, T.; Sørensen, R. Z.; Christensen, C. H.; Nørskov, J. K. Identification of non-precious metal alloy catalysts for selective hydrogenation of acetylene. Science 2008, 320, 1320-1322.

(22) Sárkány, A.; Guczi, L.; Weiss, A. H. On the aging phenomenon in palladium catalysed acetylene hydrogenation. Appl. Catal. 1984, 10, 369-388.

(23) Jin, Y.; Datye, A. K.; Rightor, E.; Gulotty, R.; Waterman, W.; Smith, M.; Holbrook, M.; Maj, J.; Blackson, J. The influence of catalyst restructuring on the selective hydrogenation of acetylene to ethylene. J. Catal. 2001, 203, 292-306.

(24) Ruta, M.; Semagina, N.; Kiwi-Minsker, L. Monodispersed Pd nanoparticles for acetylene selective hydrogenation: particle size and support effects. J. Phys. Chem. C 2008, 112, 1363513641.

(25) Yang, B.; Burch, R.; Hardacre, C.; Headdock, G.; Hu, P. Influence of surface structures, subsurface carbon and hydrogen, and surface alloying on the activity and selectivity of acetylene hydrogenation on Pd surfaces: A density functional theory study. J. Catal. 2013, 305, 264-276. 
(26) Torres, D.; Cinquini, F.; Sautet, P. Pressure and temperature effects on the formation of a $\mathrm{Pd} / \mathrm{C}$ surface carbide: insights into the role of $\mathrm{Pd} / \mathrm{C}$ as a selective catalytic state for the partial hydrogenation of acetylene. J. Phys. Chem. C 2013, 117, 11059-11065.

(27) Sarkany, A. Semi-hydrogenation of 1,3-butadiene over Pd-Ag/alpha- $\mathrm{Al}_{2} \mathrm{O}_{3}$ poisoned by hydrocarbonaceous deposits. Appl. Catal., A 1997, 165, 87-101.

(28) Hall, J. B.; Huggins, B. J.; Kaminsky, M. P.; Meyers, B. L. Deactivation mechanisms for $\mathrm{Pd} / \mathrm{Al}_{2} \mathrm{O}_{3}$ acetylene hydrogenation catalysts. 6th Ethylene Producers' Conference, Proceedings 1994, 3, 615-634.

(29) Sarkany, A.; Weiss, A. H.; Szilagyi, T.; Sandor, P.; Guczi, L. Green oil poisoning of a $\mathrm{Pd} / \mathrm{A}_{2} \mathrm{O}_{3}$ acetylene hydrogenation catalyst. Appl. Catal. 1984, 12, 373-379.

(30) Ziemecki, S. B.; Jones, G. A.; Swartzfager, D. G.; Harlow, R. L.; Faber, J. Formation of interstitial palladium-carbon phase by interaction of ethylene, acetylene, and carbon monoxide with palladium. J. Am. Chem. Soc. 1985, 107, 4547-4548.

(31) Zlemecki, S. B.; Jones, G. A. Interstitial carbon in palladium. J. Catal. 1985, 95, 621-622.

(32) Seriani, N.; Mittendorfer, F.; Kresse, G. Carbon in palladium catalysts: A metastable carbide. J. Chem. Phys. 2010, 132, 024711.

(33) Bauer, M.; Schoch, R.; Shao, L.; Zhang, B.; Knop-Gericke, A.; Willinger, M.; Schlögl, R.; Teschner, D. Structure-activity studies on highly active palladium hydrogenation catalysts by X-ray absorption spectroscopy. J. Phys. Chem. C 2012, 116, 22375-22385.

(34) Studt, F.; Abild-Pedersen, F.; Bligaard, T.; Sorensen, R. Z.; Christensen, C. H.; Norskov, J. K. On the role of surface modifications of palladium catalysts in the selective hydrogenation of acetylene. Angew. Chem., Int. Ed. 2008, 47, 9299-302. 
(35) Zaidi, A. H. Stability of Pd-C phase in the oxidation of ethylene over palladium catalysts. Appl. Catal. 1987, 30, 131-140.

(36) Zaidi, S. A. H. Structure and activity of solid solutions of carbon formed by reaction of palladium catalysts with gaseous mixtures of propylene, oxygen and acetic acid. Appl. Catal. 1987, 33, 273-280.

(37) Okitsu, K.; Mizukoshi, Y.; Bandow, H.; Yamamoto, T. A.; Nagata, Y.; Maeda, Y. Synthesis of palladium nanoparticles with interstitial carbon by sonochemical reduction of tetrachloropalladate(II) in aqueous solution. J. Phys. Chem. B 1997, 101, 5470-5472.

(38) Sarkany, A. Hydrocarbonaceous deposit assisted n-butane formation in hydrogenation of 1,3-butadiene over Pd catalysts. Appl. Catal., A 1998, 175, 245-253.

(39) Bond, G. C. The role of carbon deposits in metal-catalysed reactions of hydrocarbons. Appl. Catal., A 1997, 149, 3-25.

(40) Teschner, D.; Révay, Z.; Borsodi, J.; Hävecker, M.; Knop-Gericke, A.; Schlögl, R.; Milroy, D.; Jackson, S. D.; Torres, D.; Sautet, P. Understanding palladium hydrogenation catalysts: when the nature of the reactive molecule controls the nature of the catalyst active phase. Angew. Chem., Int. Ed. 2008, 47, 9274-9278.

(41) Teschner, D.; Borsodi, J.; Wootsch, A.; Révay, Z.; Hävecker, M.; Knop-Gericke, A.; Jackson, S. D.; Schlögl, R. The roles of subsurface carbon and hydrogen in palladium-catalyzed alkyne hydrogenation. Science 2008, 320, 86-89.

(42) Armbrüster, M.; Behrens, M.; Cinquini, F.; Föttinger, K.; Grin, Y.; Haghofer, A.; Klötzer, B.; Knop-Gericke, A.; Lorenz, H.; Ota, A.; et al. How to control the selectivity of palladiumbased catalysts in hydrogenation reactions: the role of subsurface chemistry. ChemCatChem 2012, 4, 1048-1063. 
(43) Jung, U.; Elsen, A.; Li, Y.; Smith, J. G.; Small, M. W.; Stach, E. A.; Frenkel, A. I.;

Nuzzo, R. G. Comparative in operando studies in heterogeneous catalysis: atomic and electronic structural features in the hydrogenation of ethylene over supported Pd and Pt catalysts. ACS Catal. 2015, 5, 1539-1551.

(44) Wang, J.; Wang, Q.; Jiang, X.; Liu, Z.; Yang, W.; Frenkel, A. I. Determination of nanoparticle size by measuring the metal-metal bond length: the case of palladium hydride. $J$. Phys. Chem. C 2015, 119, 854-861.

(45) Zhao, S.; Li, Y.; Stavitski, E.; Tappero, R.; Crowley, S.; Castaldi, M. J.; Zakharov, D. N.; Nuzzo, R. G.; Frenkel, A. I.; Stach, E. A. Operando characterization of catalysts through use of a portable microreactor. ChemCatChem 2015, 7, 3683-3691.

(46) Li, Y.; Zakharov, D.; Zhao, S.; Tappero, R.; Jung, U.; Elsen, A.; Baumann, P.; Nuzzo, R. G.; Stach, E. A.; Frenkel, A. I. Complex structural dynamics of nanocatalysts revealed in Operando conditions by correlated imaging and spectroscopy probes. Nat. Commun. 2015, 6 .

(47) Chupas, P. J.; Chapman, K. W.; Kurtz, C.; Hanson, J. C.; Lee, P. L.; Grey, C. P. A versatile sample-environment cell for non-ambient X-ray scattering experiments. J. Appl. Crystallogr. 2008, 41, 822-824.

(48) Al-Ammar, A. S.; Webb, G. Hydrogenation of acetylene over supported metal catalysts. Part 1.-Adsorption of [14C]acetylene and [14C]ethylene on silica supported rhodium, iridium and palladium and alumina supported palladium. J. Chem. Soc., Faraday Trans. 1 1978, 74, 195205.

(49) Stacchiola, D.; Azad, S.; Burkholder, L.; Tysoe, W. T. An investigation of the reaction pathway for ethylene hydrogenation on Pd(111). J. Phys. Chem. B 2001, 105, 11233-11239. 
(50) Tysoe, W. T.; Nyberg, G. L.; Lambert, R. M. Structural, kinetic, and reactive properties of the palladium(111)-ethylene system. J. Phys. Chem. 1984, 88, 1960-1963.

(51) McCaulley, J. A. Temperature dependence of the Pd K-edge extended x-ray-absorption fine structure of $\mathrm{PdC}_{\mathrm{x}}(\mathrm{x} \sim 0.13)$. Phys. Rev. B 1993, 47, 4873-4879.

(52) Mccaulley, J. A. In-situ X-Ray-Absorption spectroscopy studies of hydride and carbide formation in supported palladium catalysts. J. Phys. Chem. 1993, 97, 10372-10379.

(53) Tew, M. W.; Nachtegaal, M.; Janousch, M.; Huthwelker, T.; van Bokhoven, J. A. The irreversible formation of palladium carbide during hydrogenation of 1-pentyne over silicasupported palladium nanoparticles: in situ Pd K and L3 edge XAS. Phys. Chem. Chem. Phys. 2012, 14, 5761-5768.

(54) Bugaev, A. L.; Guda, A. A.; Lazzarini, A.; Lomachenko, K. A.; Groppo, E.; Pellegrini, R.; Piovano, A.; Emerich, H.; Soldatov, A. V.; Bugaev, L. A.; et al. In situ formation of hydrides and carbides in palladium catalyst: When XANES is better than EXAFS and XRD. Catal. Today 2017, 283, 119-126.

(55) McCaulley, J. A. In-situ x-ray absorption spectroscopy studies of hydride and carbide formation in supported palladium catalysts. J. Phys. Chem. 1993, 97, 10372-10379.

(56) Zabinsky, S. I.; Rehr, J. J.; Ankudinov, A.; Albers, R. C.; Eller, M. J. Multiple-scattering calculations of X-Ray-Absorption spectra. Phys. Rev. B 1995, 52, 2995-3009.

(57) Flanagan, T. B.; Oates, W. A. The palladium-hydrogen system. Annu. Rev. Mater. Sci. 1991, 21, 269-304.

(58) Ko, M. K.; Frei, H. Millisecond FT-IR spectroscopy of surface intermediates of $\mathrm{C}_{2} \mathrm{H}_{4}$ hydrogenation over $\mathrm{Pt} / \mathrm{Al}_{2} \mathrm{O}_{3}$ catalyst under reaction conditions. J. Phys. Chem. B 2004, 108, 1805-1808. 
(59) Cossee, P. Ziegler-Natta catalysis .1. Mechanism of polymerization of alpha-olefins with Ziegler-Natta catalysts. J. Catal. 1964, 3, 80-88. 


\section{TOC Graphic}

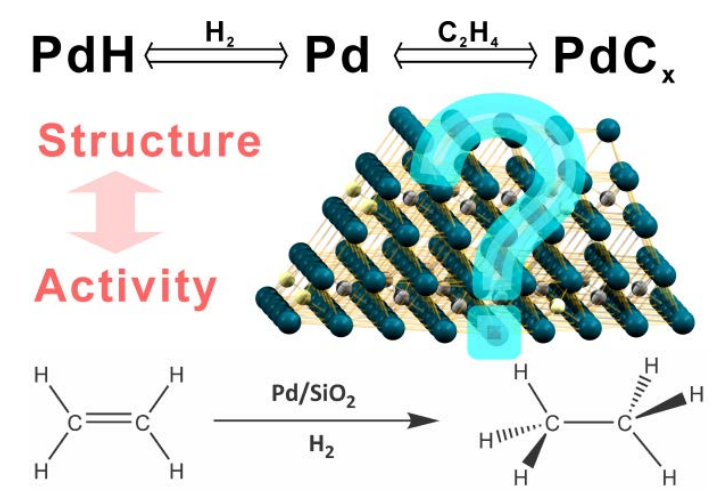

